NOTA

\title{
PRODUÇÃO E QUALIDADE DE SEMENTES DE ABOBRINHA ‘PIRAMOITA' EM RESPOSTA À QUANTIDADE DE PÓLEN ${ }^{(1)}$
}

\author{
ANTONIO ISMAEL INÁCIO CARDOSO ${ }^{(2)}$
}

\begin{abstract}
RESUMO
Realizou-se, em São Manuel (SP), um experimento com o objetivo de avaliar a influência da quantidade de pólen na produção e qualidade de sementes da abobrinha cv. Piramoita. O delineamento experimental utilizado foi em blocos casualizados, com quatro tratamentos (meia, uma ou duas flores masculinas na polinização manual de uma flor feminina e a testemunha, com polinização natural), seis repetições com dez plantas/parcela. Não se observou diferença significativa entre os tratamentos para todas as características relacionadas com produção de frutos ou sementes. Quanto à qualidade, as sementes do tratamento com polinização natural apresentaram maior germinação e vigor que os tratamentos com polinização manual, as quais não diferiram entre si.
\end{abstract}

Palavras-chave: Cucurbita moschata, frutos, polinização.

\section{ABSTRACT \\ SEED YIELD AND QUALITY IN RESPONSE TO POLLEN LOAD OF SQUASH CV. PIRAMOITA}

A field trial was carried out in São Manuel, State of Sao Paulo, Brazil, to evaluate the influence of pollen load on fruit and seed production and seed quality of squash, cv. Piramoita. The experimental design was a randomized block, with six replicates of 10 plants/plot and four treatments: half, one or two male flowers, in manual pollination of one female flower and a control, with natural pollination. The results revealed differences not significant among the treatments for the characteristics related to fruit and seed production. Higher quality (germination and vigor) was obtained with natural pollination, while different pollen load did not affect seed quality.

Key words: Cucurbita moschata, flowers, pollination, fruits.

(1) Departamento de Produção Vegetal - Horticultura, Faculdade de Ciências Agronômicas, Universidade Estadual Paulista,Caixa Postal 237, 18603-970, Botucatu (SP). E-mail: ismaeldh@fca.unesp.br 


\section{Introdução}

A utilização de sementes de cultivares adaptadas e de alta qualidade fisiológica, sanitária e genética é um fator primordial na produção de hortaliças. A difusão do uso de híbridos levaram os produtores a exigirem alta qualidade da semente, já que seu preço é superior aos das cultivares de polinização aberta.

No caso de cucurbitáceas, é importante salientar que a polinização manual é uma alternativa utilizada na produção de sementes de híbridos. Nesse caso, tanto o progenitor masculino quanto a quantidade de pólen podem ser controlados de acordo com a necessidade.

Durante o processo de produção de sementes híbridas de abóbora, PESSOA (1998) citou que há três fases importantes e que merecem especial atenção: polinização, fertilização e desenvolvimento dos frutos.

A polinização, processo pelo qual o grão-depólen é transportado das anteras das flores masculinas para o estigma das flores femininas, é entomófila; LOPES E CASALI (1982) citaram que abelhas Apis mellifera e Trigona rufricus são os principais agentes polinizadores das cucurbitáceas.

Segundo Ávila et al. (1989), a polinização manual na obtenção de híbridos de abobrinha foi tão efetiva quanto a polinização natural com respeito ao número de frutos por planta, porém, menos efetiva em relação à produção de sementes por planta. Schlichiting et al. (1987) relataram que uma elevada quantidade de pólen aplicada resultou em frutos maiores e com maior quantidade de sementes do que uma baixa quantidade. Também Lima (2000) obteve maior produção de sementes em abobrinha 'Caserta' (C. pepo) quando foi aplicado pólen de uma flor masculina, comparado ao pólen de meia flor. A polinização natural foi superior à utilização de meia flor, mas não diferiu da utilização de uma flor masculina em polinização manual.

QuESADA et al. (1996) observaram que sementes híbridas de abobrinha, produzidas com elevada quantidade de pólen, germinavam mais rapidamente. O estudo demonstrou a correlação positiva entre a quantidade de pólen e o vigor da progênie resultante.

STEPHENSON el al. (1988) observaram que os frutos contendo elevada quantidade de sementes cresciam mais rápido e alcançavam tamanho maior do que aqueles com poucas sementes. Os autores constataram que um elevado número de sementes nos primeiros frutos a se desenvolverem na planta, aumentava a possibilidade de abortamento de novos frutos.
Frutos com menos sementes abortaram mais do que os frutos com as maiores quantidades de sementes. Concluíram que o número de sementes por fruto e a competição de frutos na planta são fatores fundamentais no pegamento de novos frutos e na produtividade de sementes. Esse processo de abortamento pode ser um mecanismo pelo qual as plantas podem influenciar, de alguma maneira, a qualidade de suas sementes e progênie (LEE, 1984).

Assim as plantas, indiretamente, eliminam as progênies produzidas com pouca competição entre grãos-de-pólen, aumentando o vigor e qualidade da descendência.

Para os produtores de sementes, grande quantidade de pólen depositado sobre o estigma pode ser favorável tanto em relação à produtividade como à qualidade das sementes produzidas. Para o melhorista, há a possibilidade de se selecionar populações mais vigorosas apenas expondo as flores femininas a uma grande quantidade de pólen, sem a necessidade de grandes áreas, apenas aproveitando a intensa competição entre os grãos-de-pólen (DAVIS et al., 1987).

O objetivo da pesquisa foi avaliar a influência da quantidade de pólen colocado sobre o estigma de flores de abobrinha, cultivar Piramoita, na produção e qualidade de sementes.

\section{Material e Métodos}

O experimento foi realizado na Fazenda Experimental São Manuel, pertencente à Faculdade de Ciências Agronômicas - UNESP, localizada no município de São Manuel (SP), longitude: $48^{\circ} 34^{\prime} \mathrm{W}$, latitude: $22^{\circ} 44^{\prime} \mathrm{S}$ e altitude média de $750 \mathrm{~m}$. As análises de sementes foram realizadas no Departamento de Produção Vegetal, da FCA, em Botucatu (SP).

O delineamento experimental foi em blocos ao acaso, com quatro tratamentos, seis repetições e dez plantas por parcela. Foram estudadas três diferentes quantidades de pólen na polinização manual: metade, uma e duas quantidades médias de pólen de uma flor masculina, colocadas sobre a superfície do estigma de uma flor feminina da cultivar Piramoita. O quarto tratamento constou da polinização livre, ou natural, feita por insetos no campo. Esse tratamento visou comparar a qualidade da polinização manual com a natural.

O solo apresentou teores médios ou altos para a maioria dos nutrientes (RAIJ et al., 1996), como mostram os resultados da análise química: matéria orgânica $=10 \mathrm{~g} \cdot \mathrm{dm}^{-3} ; \mathrm{P}_{\text {resina }}=73 \mathrm{mg} \cdot \mathrm{dm}^{-3} ; \mathrm{K}=1,7$ $\mathrm{mmol}_{\mathrm{c}} \cdot \mathrm{dm}^{-3} ; \mathrm{Ca}=19 \mathrm{mmol}_{\mathrm{c}} \cdot \mathrm{dm}^{-3} ; \mathrm{Mg}=9 \mathrm{mmol}_{\mathrm{c}} \cdot \mathrm{dm}^{-3}$; $\mathrm{CTC}=44 \mathrm{mmol}_{\mathrm{c}} \cdot \mathrm{dm}^{-3}$; saturação por bases $=66 \% ; \mathrm{pH}$ $\left(\mathrm{CaCl}_{2}\right)=5,7$. 
A adubação do solo constou da aplicação de composto orgânico (5 L.m ${ }^{-2}$ ), adubo formulado 8-28$16\left(100 \mathrm{~g} \cdot \mathrm{m}^{-2}\right)$ e nitrocálcio $\left(50 \mathrm{~g} \cdot \mathrm{m}^{-2}\right)$. As adubações em cobertura foram realizadas a cada 14 dias colocando-se $5 \mathrm{~g}$ por planta de adubo formulado 20-05-20.

A irrigação foi feita por aspersão, no período da tarde, para facilitar o trabalho dos insetos polinizadores. Realizou-se o controle de brocas e oídio, principais problemas fitossanitários observados. Para a realização da polinização manual, as pontas das pétalas das flores masculinas e femininas selecionadas, ainda fechadas, foram amarradas com lã na tarde anterior ao cruzamento.

A polinização foi feita na manhã seguinte, encostando-se as anteras nos estigmas das flores femininas, deixando todo o pólen aderido. Para dividir a antera ao meio, utilizou-se uma lâmina de barbear. Esse tratamento visou simular o que ocorre usualmente, ou seja, a menor quantidade de flores masculinas em relação às femininas, geralmente por falta de sincronização no florescimento entre os progenitores.

Anteras fora do padrão, pequenas ou com pouco pólen, foram descartadas. Em média, foram obtidos $24 \mathrm{mg}$ de pólen em cada flor masculina. Após a polinização, efetuou-se a identificação da data do cruzamento com uma etiqueta amarrada ao pedúnculo da flor feminina, que foi protegida com um saquinho de papel.

Para garantia do estande ideal, a semeadura foi feita em bandejas de poliestireno expandido de 128 células, colocando-se uma semente por célula, em 13 de agosto de 2001. As plantas foram transplantadas quando estavam emitindo a segunda folha verdadeira (aos 22 dias após a semeadura), no espaçamento de $2,0 \times 1,5 \mathrm{~m}$.

Os cruzamentos manuais estenderam-se de 18 a 31 de outubro de 2001. Para evitar qualquer efeito da idade dos frutos nos tratamentos com polinização manual, colheram-nos no estádio de maturação morfológica, ao atingir coloração creme, cerca de 45 dias após a polinização; depois, foram deixados sete dias em ambiente sombreado para completar a maturação das sementes, conforme recomendação de Araújo et al. (1982) e Pedrosa et al. (1987).

Para a extração das sementes, os frutos foram cortados e as sementes lavadas em peneira, retirando-se a polpa. As sementes foram secadas à sombra por 72 horas.

A limpeza, para retirada das chochas e danificadas, foi feita em aparelho separador por densidade (modelo 'De Leo Tipo 1', calibrado em uma abertura correspondente a 50\% da área da saída do ar).
Em seguida, foram armazenadas em câmara seca $\left(\mathrm{UR}=40 \%\right.$, temperatura $\left.=20{ }^{\circ} \mathrm{C}\right)$, onde o teor de água das sementes se estabilizou por volta de 8,0\%. Foram deixados, no máximo, dois frutos por planta, inclusive na testemunha, para evitar que a competição prejudicasse principalmente o pegamento de frutos das polinizações manuais, pois é comum o aborto de grande número de frutos em abóbora.

Avaliaram-se as seguintes características: pegamento de frutos - \% das polinizações manuais que resultaram em frutos maduros, apenas para os tratamentos com polinização manual; massa média de fruto - em g; produção de sementes por fruto, onde foram contabilizados massa $(\mathrm{g})$ e número de sementes classificadas; produção em massa (g) e número de sementes por polinização realizada - foi obtida dividindo-se a produção de sementes em cada parcela pelo número de flores polinizadas manualmente (apenas para os tratamentos com polinização manual); massa de 100 sementes, em g; germinação - foi realizado o teste de germinação para sementes de abobrinha conforme as regras para análise de sementes (BRASIL, 1992).

As amostras foram deixadas em rolo de papel à temperatura constante de $25^{\circ} \mathrm{C}$. A primeira leitura foi realizada aos quatro e a segunda, aos oito dias. Foram mantidas as parcelas originais do experimento de campo, utilizando-se uma amostra dos frutos colhidos em cada parcela; vigor das sementes: a) primeira leitura no teste de germinação (BRASIL, 1992); b) índice de velocidade de emergência (IVE) - realizou-se semeadura em bandejas de poliestireno expandido (128 células), contendo substrato comercial, sob temperatura ambiente (variando de 5 a $25{ }^{\circ} \mathrm{C}$, no período de 5 a 24 de junho de 2002).

As avaliações de emergência foram iniciadas aos seis dias após a semeadura, estendendo-se até os 19 dias, quando as plântulas mais vigorosas apresentavam o início de expansão da segunda folha definitiva (ponto de transplante).

Realizou-se o cálculo de índice de velocidade de emergência através do somatório do número de plantas emergidas em cada dia, não cumulativo, dividido pelo número de dias decorridos entre a semeadura e a emergência (MARCos FILHO et al., 1987), de acordo com a fórmula : $\mathrm{IVE}=\mathrm{E} 6 / 6+\mathrm{E} 7 / 7+\mathrm{E} 8 /$ $8+\ldots+\mathrm{E} 19 / 19$; onde: $\mathrm{E} 6, \mathrm{E} 7, \ldots \mathrm{E} 19=$ número de plântulas emergidas no $6^{\circ}, 7^{\circ}, \ldots 19^{\circ}$ dia; c) emergência em substrato - utilizou-se a última leitura feita no teste de emergência em substrato, como o valor de potencial de emergência das sementes. Os valores obtidos foram submetidos à análise de variância e as médias dos tratamentos foram comparadas pelo teste de Tukey a $5 \%$. 


\section{Resultados e Discussão}

A quantidade de pólen utilizada na polinização manual não afetou significativamente o pegamento de flores polinizadas manualmente (variou de 62,6 a $64,4 \%$ ) e a massa média de frutos (1606 a $1960 \mathrm{~g}$ ), bem como o número (221 a 246 sementes) e a massa de sementes $(22,8$ a $23,9 \mathrm{~g})$ por fruto e por polinização (173 a 192 sementes e 17,9 e 18,8 g).

$O$ resultado contrasta com o relatado por Schlichting et al. (1987), Quesada et al. (1996) e Lima (2000) que obtiveram maior produção de sementes em função da quantidade de pólen utilizada na polinização manual. Entretanto, foram utilizadas populações e espécies diferentes.

Por exemplo, LiMA (2000), trabalhando com abobrinha cv. Caserta (C. pepo), relatou uma quantidade aproximada de $13 \mathrm{mg}$ de pólen em cada flor masculina, enquanto na população estudada (cv. Piramoita, C. moschata) foram obtidos aproximadamente $24 \mathrm{mg}$ de pólen em cada flor masculina.

Desse modo, o pólen de meia flor pode ter sido suficiente para cobrir toda a superfície do estigma de uma flor feminina, podendo ser essa a causa da ausência de diferença entre os tratamentos avaliados.

Também não houve diferença entre a polinização manual e a natural, mostrando que a manual foi tão efetiva quanto a natural, pois foram obtidos frutos de igual massa (1606 e $1923 \mathrm{~g}$ / fruto na polinização natural e manual respectivamente) e com a mesma quantidade de sementes (241 e 235 sementes/fruto nas polinizações natural e manual respectivamente).

Por sua vez, Ávila et al. (1989) obtiveram maior massa de fruto e maior produção de sementes por planta no progenitor feminino da abobrinha
'Clarinda' (C. pepo) com a polinização natural por insetos quando comparada com a polinização manual utilizando uma flor masculina para cada flor feminina.

Os motivos podem ter sido, como já exposto, a grande quantidade de pólen em cada flor masculina na população estudada ou diferenças na quantidade ou atividade dos insetos polinizadores, que pode variar de acordo com as condições climáticas, vegetação competitiva periférica e a própria população de insetos.

Visualmente, foi observada grande quantidade de insetos, sobretudo dos gêneros Apis e Trigona. Portanto, dificilmente foi por falta de insetos polinizadores, uma vez que esse tratamento (polinização natural) foi o que apresentou sementes com melhor qualidade, conforme será discutido.

Os valores obtidos para número de sementes/ fruto foram superiores aos relatados por ÁviLA et al. (1989), em C. pepo, que obtiveram 150 e 120 sementes por fruto, mas semelhantes aos obtidos por LiMA (2000), que obteve de 210 a 262 e 171 a 295 sementes por fruto na polinização natural e manual (uma flor) respectivamente.

Com relação à qualidade das sementes (Quadro 1), não se observaram diferenças significativas entre os tratamentos para a massa de 100 sementes. Para algumas espécies, existe relação entre vigor e tamanho da semente (CARvalho e Nakagawa, 2000), devido à quantidade de reserva energética (VIEIRA e CARVALHO, 1994).

Não se confirmou essa relação entre o peso de 100 sementes e vigor, pois, apesar de não haver diferença no peso de 100 sementes, foram obtidos maiores valores para germinação e vigor (primeira contagem e índice de velocidade de emergência) no tratamento com polinização natural em relação aos tratamentos com polinização manual (Quadro 1).

Quadro 1. Massa de 100 sementes (P100Sem), primeira e segunda contagem no teste padrão de germinação, total de plântulas emergidas em substrato (PlEmerg) e índice de velocidade de emergência (IVE) de acordo com o tratamento. São Manuel, FCA/UNESP, 2001

\begin{tabular}{lccccc}
\hline & P100Sem & 1. ${ }^{\mathrm{a}}$ contagem & 2. $^{\mathrm{a}}$ contagem & PlEmerg & IVE \\
\cline { 2 - 5 } Polinização natural & $\mathrm{g}$ & $56 \mathrm{a}$ & $88 \mathrm{a}$ & $92,0 \mathrm{a}$ & $3,51 \mathrm{a}$ \\
0,5 flor masculina & $9,93 \mathrm{a}$ & $38 \mathrm{~b}$ & $72 \mathrm{ab}$ & $78,7 \mathrm{ab}$ & $3,18 \mathrm{~b}$ \\
1 flor masculina & $10,25 \mathrm{a}$ & $36 \mathrm{~b}$ & $66 \mathrm{~b}$ & $76,8 \mathrm{~b}$ & $3,12 \mathrm{~b}$ \\
2 flores masculinas & $9,75 \mathrm{a}$ & $33 \mathrm{~b}$ & $70 \mathrm{~b}$ & $75,7 \mathrm{~b}$ & $3,12 \mathrm{~b}$ \\
\hline C.V. $(\%)$ & $9,92 \mathrm{a}$ & 15,9 & 7,7 & 5,0 & 5,6 \\
\hline
\end{tabular}

Médias seguidas pela mesma letra, na coluna, não diferem estatisticamente pelo teste de Tukey a 5\% de probabilidade. 
Lotes de sementes com maior vigor, principalmente maior índice de velocidade de emergência são importantes para a obtenção de plântulas que fiquem menos tempo sob condições adversas, como tombamento ou, também, pela obtenção de mudas mais precoces e mais uniformes. Para a germinação total (segunda contagem) e emergência total, o tratamento com a utilização de meia flor masculina não diferiu da polinização natural. Pode ter havido pequeno efeito do maior peso de sementes, embora não tenha sido estatisticamente diferente dos demais.

É difícil explicar a melhor qualidade das sementes com polinização natural, tendo em vista que não houve diferença na produção de sementes, na massa de sementes e na massa média de fruto; inclusive, a polinização natural resultou em frutos com menor massa, embora estatisticamente sem diferença com os tratamentos com polinização manual (1.606 e $1.923 \mathrm{~g}$ / fruto na polinização natural e manual respectivamente). Entretanto, o fato repetiu-se em todos os testes de qualidade de sementes.

É possível que o manuseio das flores ou a colocação manual do pólen possa ter afetado os órgãos florais femininos a ponto de afetar a qualidade da semente.

Ao contrário, a polinização entomófila não prejudica o processo de fertilização e a maturação das sementes. Além disso, a cultivar utilizada pode ser mais sensível ao manuseio das flores. Também, podese supor que na polinização natural a própria planta "selecione" os frutos para favorecer a descendência (sementes) mais vigorosa, ou seja, apenas as melhores flores femininas se desenvolvem em frutos, gerando sementes de melhor qualidade (LEE, 1984).

Já na polinização manual, apenas uma ou no máximo duas flores foram polinizadas, não propiciando competição entre flores femininas e frutos pequenos. Apenas essas flores polinizadas tiveram chance de completar o processo de maturação das sementes.

Nos tratamentos com polinização manual, a quantidade de pólen não afetou as características relacionadas à qualidade de sementes (Quadro 1), contrariando resultados obtidos por DAvis et al. (1987). Esses autores relataram que sementes de abobrinha produzidas sob condições de elevada quantidade de pólen podem originar sementes de melhor qualidade, pois grãos de pólen vigorosos seriam mais competitivos, aumentando a chance de fertilizar os óvulos e gerar sementes mais vigorosas. Lima (2000) também obteve sementes mais vigorosas, quando utilizou uma flor em relação à meia flor na polinização manual de abóbora.

\section{Conclusão}

1. Para as condições do experimento pode-se concluir que a quantidade de pólen e/ou o tipo de polinização não afetou a produção das sementes, embora tenham sido obtidas sementes com melhor qualidade (germinação e vigor) na polinização natural.

\section{Agradecimentos}

O autor agradece à FAPESP (processo n. $.^{\circ} 01 /$ 04400-6) pelo auxílio financeiro.

\section{Referências Bibliográficas}

ARAÚJO, E.F.; MANTOVANI, E.C.; SILVA, R.F. Influência da idade e armazenamento dos frutos na qualidade de sementes de abóbora. Revista Brasileira de Sementes, Brasília, v.4, n.1, p.77-87, 1982.

ÁVILA, C.J.; MARTINHO, M.R.; CAMPOS, J.P. Polinização e polinizadores na produção de frutos e sementes híbridas de abóbora (Cucurbita pepo var. melopepo). Anais da Sociedade Entomológica do Brasil, Piracicaba, v.18, n.1, p.13-19, 1989.

BRASIL. Ministério da Agricultura e Reforma Agrária. Regras para análise de sementes. Brasília: SNAD/CLAV, 1992. 365p.

CARVALHO, N.M.; NAKAGAWA, J. Sementes: ciência, tecnologia e produção. 4.ed. Jaboticabal: FUNEP, 2000. 588p.

DAVIS, L. E.; STEPHENSON, A. G.; WINSOR, J. A. Pollen competition improves performance and reproductive output of the common zucchini squash under field conditions. Journal of the American Society for Horticultural Science, New York, v.112, n.4, p.712-716, 1987.

LEE, T.D. Patterns of fruit maturation: a gametophyte competition hypothesis. American Naturalist, Chicago, n.123, p.427-432, 1984

LIMA, M.S. Espaçamento entre plantas e quantidade de pólen na produção e qualidade de sementes de abobrinha (Cucurbita pepo). 2000. 75f. Dissertação (Mestrado) - Faculdade de Ciências Agronômicas, Botucatu.

LOPES, J.F.; CASALI, V.W.D. Produção de sementes de cucurbitáceas. Informe Agropecuário, Belo Horizonte, v.8, n.85, p.65-68, 1982.

MARCOS FILHO, J.; CÍCERO, S.M.; SILVA, W.R. Avaliação da qualidade das sementes. Piracicaba: FEALQ, 1987. 230p.

PEDROSA, J.F.; ALVARENGA, M.A.R.; FERREIRA, F.A.; CASALI, V.W.D. Abóboras, morangas e abobrinhas: cultivares e métodos culturais. Informe Agropecuário, Belo Horizonte, v.8, n.85, p.24-25, 1982.

PESSOA, H.B.S.V. Produção de sementes híbridas de abóbora do tipo tetsukabuto. Circular Técnica da Embrapa Hortaliças, Brasília, n.12, p.1-9, 1998. 
QUESADA, M.; WINSOR, J.A.; STEPHENSON, A.G. Effects of pollen selection on progeny vigor in Cucurbita pepo $\times$ C. texana hybrid. Theoretical and Applied Genetics, Berlin, v.92, n.7, p.885890, 1996.

RAIJ, B.Van; CANTARELLA, H.; QUAGGIO, J.A.; FURLANI, M.C. Recomendações de adubação e calagem para o Estado de São Paulo. 2ed. Campinas: Instituto Agronômico \& Fundação IAC, 1996. 285p. (Boletim, 100)

SCHLICHTING, C. D.; DAVIS, L. E.; STEPHENSON, A. G.; WINSOR, J. A. Pollen competition and offspring variance. Evolutionary Trends in Plants, Royal, v.1, n.1, p.35-39, 1987.
SILVA, J.B.; NAKAGAWA, J. Estudo de fórmulas para cálculo da velocidade de germinação. Informativo ABRATES, Brasília, v.5, n.1, p.62-73, 1995.

STEPHENSON, A.G.; DEVLIN, B.; HORTON, J.B. The effects of seed number and prior fruit dominance on the pattern of fruit production in Cucurbita pepo (zucchini squash). Annals of Botany, London, v.62, n.6, p. 653-661, 1988.

VIEIRA, R.D., CARVALHO, N.M. Teste de vigor em sementes. Jaboticabal: FCAV/FUNEP, 1994. 164p. 